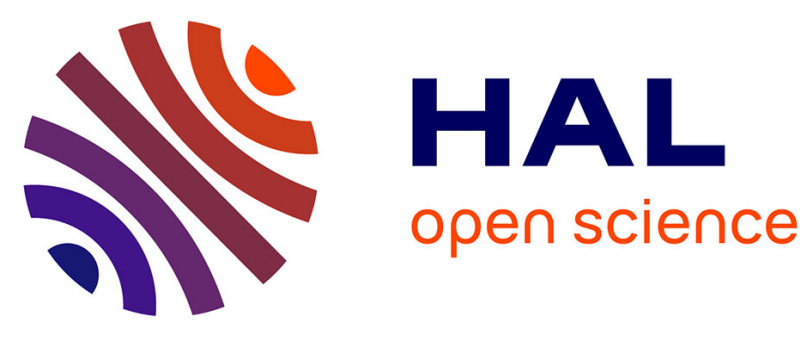

\title{
Fluctuation analysis of postoperative secretory status in patients operated for acromegaly
}

Thomas Graillon, Frederic Castinetti, Mohamed Boucekine, Thomas Cuny, Isabelle Morange, Stéphane Fuentes, Dominique Figarella-Branger, Frédérique Albarel, Thierry Brue, Henry Dufour

\section{To cite this version:}

Thomas Graillon, Frederic Castinetti, Mohamed Boucekine, Thomas Cuny, Isabelle Morange, et al.. Fluctuation analysis of postoperative secretory status in patients operated for acromegaly. Annales d'Endocrinologie, 2020, 81 (1), pp.11-17. 10.1016/j.ando.2019.11.002 . hal-03223199

\section{HAL Id: hal-03223199 \\ https://hal-amu.archives-ouvertes.fr/hal-03223199}

Submitted on 12 May 2021

HAL is a multi-disciplinary open access archive for the deposit and dissemination of scientific research documents, whether they are published or not. The documents may come from teaching and research institutions in France or abroad, or from public or private research centers.
L'archive ouverte pluridisciplinaire HAL, est destinée au dépôt et à la diffusion de documents scientifiques de niveau recherche, publiés ou non, émanant des établissements d'enseignement et de recherche français ou étrangers, des laboratoires publics ou privés.

\section{(ㅇ)(1) $\$$}

Distributed under a Creative Commons Attribution - NonCommercial - NoDerivatives 44.0 


\title{
Fluctuation analysis of postoperative secretory status in patients operated for acromegaly
}

\author{
Analyse des fluctuations sécrétoires chez les patients opérés pour acromégalie
}

\author{
Thomas Graillon a,b,* , Frédéric Castinetti ${ }^{\mathrm{b}, \mathrm{c}}$, Mohamed Boucekine ${ }^{\mathrm{d}}$, Thomas Cuny ${ }^{\mathrm{b}, \mathrm{c}}$, \\ Isabelle Morange $^{c}$, Stéphane Fuentes ${ }^{a}$, Dominique Figarella-Branger ${ }^{\mathrm{e}}$, \\ Frédérique Albarel ${ }^{\mathrm{c}}$, Thierry Brue ${ }^{\mathrm{b}, \mathrm{c}}$, Henry Dufour ${ }^{\mathrm{a}, \mathrm{b}}$ \\ a Neurosurgery department, CHU Timone, Aix-Marseille university, AP-HM, Marseille, France \\ ${ }^{\mathrm{b}}$ Inserm, MMG, Aix-Marseille university, Marseille, France \\ ${ }^{c}$ Endocrinology department, CHU Conception, Aix-Marseille university, AP-HM, Marseille, France \\ d EA 3279 CEReSS, Health service research and quality of life center, La Timone Medical Campus, School of medicine, Aix-Marseille university, 27, boulevard, \\ Jean-Moulin cedex 05, 13385 Marseille, France \\ e Service d'anatomie pathologique et de neuropathologie, CNRS, INP, Inst. neurophysiopathol, CHU Timone, Aix-Marseille university, AP-HM, Marseille, \\ France
}

Keywords:

Acromegaly

Classification

$\mathrm{GH}$

IGF-1

Recurrence

Outcome

\section{A B S T R A C T}

Objective. - The aim of this study was to describe endocrinological outcome in patients operated on for acromegaly.

Methods. - A retrospective study included 167 patients. Patients were assessed in the early postoperative period (EPP), at 3 months (M3), at 1 year (Y1), and then annually. They were classified as grade I (IGF-1 level normal-for-age and positive GH response on oral glucose tolerance test [nadir $<0.4 \mathrm{ng} / \mathrm{L}$ ]); grade II (discordant); or grade III or IV (acromegaly, controlled or uncontrolled under medical therapy, respectively).

Results. - Taking all patients with all grades, 35\% changed grades between EPP and M3, 26\% between M3 and $\mathrm{Y} 1$ and $9 \%$ after Y1. In grade I, respectively 22\%, 15\% and 2\% of patients changed grades between EPP and M3, between M3 and Y1, and after Y1, compared to 31\%,6\% and 6\% in grade IV. Respectively 57\%, $67 \%$, and $47 \%$ of grade II patients changed grades between EPP and M3, between M3 and Y1, and after Y1; between EPP or M3 and last follow-up (>1 year), respectively 74\% and 75\% of grade II patients changed grades. Knosp category, resection quality and abnormal GH response (vs. abnormal IGF-1) significantly impacted grade II patients' outcome.

Conclusions. - Whereas outcome in grades I and III-IV seems to be determined by 1 year, grade II discordant patients' outcome remains uncertain even after 1 year.

\section{R É S U M É}

Objectif. - L'objectif de ce travail est de décrire le pronostic endocrinien des patients opérés d'une acromégalie.

Méthodes. - Au total, 167 patients ont été inclus dans cette étude rétrospective. Les patients ont été évalués en postopératoire précoce (POP), à 3 mois (M3), à 1 an (A1) et puis tous les ans. Les patients ont été classés en 4 grades. Grade I : IGF-1 normale compte tenu de l'âge, et présence d'une réponse de l'hormone de croissance $(\mathrm{GH})$ au test oral de tolérance au glucose (nadir $<0,4 \mathrm{ng} / \mathrm{L}$ ) ; grade II : patients discordants ; grades III et IV : acromégalie contrôlée ou non contrôlée sous traitement médical, respectivement.

\footnotetext{
* Corresponding author. Service de neurochirurgie, hôpital La Timone, 264, rue Saint-Pierre, 13005 Marseille, France. E-mail addresses: Thomas.Graillon@ap-hm.fr, tom.graillon@free.fr (T. Graillon).
} 
Résultats. - En prenant en compte tous les patients avec différents grades, 35 \% ont changé de grade entre POP et M3, $26 \%$ entre M3 et A1, et $9 \%$ après la première année. Respectivement, 22,15 et $2 \%$ des patients grade I, et 31,6 et $6 \%$ des patients grade IV ont changé de grade au cours des 3 premiers mois, entre M3 et A1 et après la première année. Respectivement, 57, 67 et 47 \% des patients grade II ont changé de grade au cours des 3 premiers mois, entre M3 et A1 et après la première année. Entre POP ou M3 et le dernier suivi (>1 an), respectivement 74 et $75 \%$ des patients de grade II ont changé de grade. La classification de Knosp, la qualité d'exérèse et l'absence de réponse du taux de GH (vs IGF-1 anormale) ont un impact pronostique significatif chez les patients de grade II.

Conclusions. - Alors que le pronostic endocrinien des patients grades I et III-IV semble défini à 1 an, le pronostic des patients grade II discordants demeure incertain, même après la première année.

\section{Introduction}

Acromegaly is a rare disease typically caused by a growth hormone $(\mathrm{GH})$-secreting pituitary adenoma for which transsphenoidal surgery is the first-line treatment. According to recent guidelines, remission is defined as $\mathrm{GH}$ levels of $<0.4 \mathrm{ng} / \mathrm{mL}$ after an oral glucose tolerance test (OGTT; except in patients with glucose disorders for whom a mean of $\mathrm{GH}$ samples should be $<1 \mathrm{ng} / \mathrm{mL}$ ) and reference age-appropriate insulin-like growth factor (IGF-1) levels. This definition of remission raises the point of the final status of patients with discordant GH and IGF-1 levels (i.e., suppressed GH with increased IGF-1, or normal IGF-1 and unsuppressed GH). We previously reported that up to a fourth of our patients operated for acromegaly had a 3-month evaluation with discordant GH and IGF1 levels [1]. Although endocrinologists are used to dealing with this discrepancy in clinical practice for many years, discordant patients' outcome remains uncertain and undefined [2,3]. Most neurosurgical studies focusing on acromegaly outcomes classify patients with operated acromegaly as cured or uncured, without considering discordant hormone levels obviously also related to biological threshold of GH and IGF-1 level [1].

Nevertheless, it is now commonly accepted that, after the surgery and then the determination of the endorinological final status, the outcome of acromegaly comorbidities is obviously correlated to the residual GH hypersecretion. Holdaway et al. reported that patients with GH hypersecretion had an increased morbidity and mortality rate, because of cardiovascular disease and stroke [4]. Therefore, the management of patients with acromegaly should also be aimed at explaining the probability of obtaining normal $\mathrm{GH}$ hypersecretion with appropriate means [5]. Comparison of the efficacy of techniques is however difficult because of the lack of a universal definition of cured/uncured/uncertain remission or control of GH hypersecretion.

In this study, we aimed to describe the endocrinological outcome of patients operated for acromegaly in a single tertiary referral center, with the description of a new classification. This classification aims to facilitate the study analysis and could also help the physician in clinical practice to determine the probability of recurrence at a given timeframe of follow-up.

\section{Material and methods}

\subsection{Patient characteristics}

Patients operated for newly-diagnosed acromegaly in our department between 1997 and 2014 were included in the study. Patients who were not followed-up in our endocrinology department were excluded. Endocrine assessment including OGTT was performed in the early postoperative period (EPP) corresponding approximately to 7 postoperative days, at 3 months (M3), at one year (Y1) then every year. Twenty-tree patients (14\%) did not
Table 1

GH-secreting patient status classification.

\begin{tabular}{ll}
\hline & GH-secreting patient status \\
\hline Grade I & Normal IGF-1 (age-gender) and HPO GH $<1,2 \mathrm{mU} / \mathrm{L}(0,4 \mathrm{ng} / \mathrm{mL})$ \\
& No therapy \\
Grade II & IGF-1 non-normalized or GH slowdown \\
& IGF-1 normalized or GH non-slowdown \\
& No therapy \\
Grade III & Controlled under therapy whatever the therapy combination \\
Grade IV & IVA: non-controlled and non-treated \\
& IVB: non-controlled under therapy \\
R & Treated by radiotherapy or radiosurgery
\end{tabular}

achieve OGTT related mainly to diabetes mellitus. Pituitary magnetic resonance imaging (MRI) was performed at 3 months, 1 year, then every year after the surgery. The MRI results were interpreted by an independent neuroradiologist. Neuropathological status of each tumor was based on its atypical features, mitosis number, and immunohistochemical characters. Patients still treated by somatostatin therapy in the month before surgery were not included. Patients treated by pegvisomant and somatostatin analogs during the follow-up were assessed by IGF-1 and classified as grade III or grade IVB depending on IGF-1 level. Proliferation index Ki-67 and p53 expression were collected for 2008-2014 series. Cavernous sinus invasion was defined as a grade 3 or 4 Knosp. Peroperative neurosurgeon findings were collected and resumed as likely complete, uncertain complete, or incomplete. Outcome analyses only included patients with follow-up of $>1$ year. The present study received approval from the ethics committee of the Aix-Marseille University.

\subsection{Classification definition}

Patients were classified into four grades according to IGF-1 and GH secretion to simplify study analysis (Table 1). Those with acromegaly remission defined as normalized-age IGF-1 level and normal OGTT GH response (nadir $<0.4 \mathrm{ng} / \mathrm{L}$ ), or a mean $\mathrm{GH}$ level of $<1.0 \mathrm{ng} / \mathrm{L}$ in patients with glucose disorders were included in grade I. Discordant non-treated patients with normal IGF-1 and abnormal GH response to OGTT (or mean GH $>1 \mathrm{ng} / \mathrm{L}$ ) or abnormal IGF-1 and normal GH response to OGTT (or normal basal GH) were included in grade II. Grade III patients represented those with acromegaly controlled under medical therapy. Grade IV patients represented those with uncontrolled acromegaly without treatment (grade IVA) or under treatment (grade IVB). Letter "R" was added for patients who had received radiotherapy or radiosurgical treatment.

\subsection{Recurrence definition}

Recurrence was biologically defined by grade III and IV (elevated IGF-1 and GH) at the last follow-up (in case of follow-up > 1 year) in 


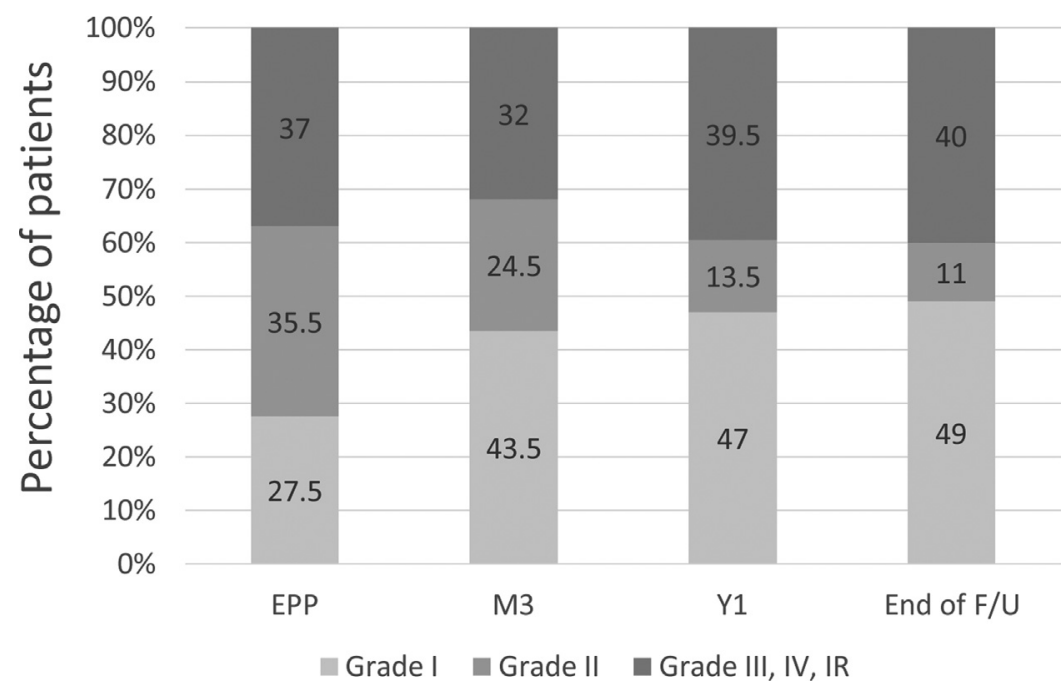

Fig. 1. Grade distribution during the follow-up (EPP: early postoperative period; M3: 3 months; Y1: 1 year; End of F/U: end of follow-up).

previously grade I and II patients at the EPP and 3 months. Tumor residue visualized on MRI was not required to define recurrence. Grade IR patients corresponded to those with recurrence cured by radiotherapy or radiosurgery, and these patients were considered as recurred in statistical analyses. Grade III-IV patients at the EPP remaining grade III-IV at M3, Y1 and at the end of follow-up were considered as uncured.

\subsection{Statistical analysis}

Quantitative variables are presented as mean and standard deviation or median and interquartile range, and were compared using the Mann-Whitney test. Qualitative variables are presented as numbers and rate, and were compared using $\mathrm{Chi}^{2}$ or Fischer exact test. For each grade (I, II, IV) and time (EPP, M3, Y1), the associations between recurrence and likely complete resection, uncertain complete resection, and incomplete resection; CS invasion; and abnormal IGF-1/abnormal GH response to OGTT factors were analyzed using univariate Firth's bias-reduced logistic regression [6]. Odds ratios are displayed with $95 \%$ confidence interval (CI). A twosided $P$-value of $<0.05$ was considered as statistically significant. Statistical analysis was performed using R software "logistf" package. Statistical association between pretreatment and grade I or grade II status at the EPP was analyzed by contingency table and $\mathrm{Chi}^{2}$ test. Statistical association between pretreatment and grade II or III-IV patients at the last follow-up ( $\square 1$ year) was also analyzed by contingency table and $\mathrm{Chi}^{2}$ test.

\section{Results}

A total of 167 patients were included in this retrospective study. The female-to-male ratio in the study was 1.4 , the mean age of the included patients was 58 years, the median follow-up period was 35 (3-135) months, and the median follow-up of patients with follow-up duration of $>1$ year was 60 (18-135) months. In all, $104 / 167$ patients (62\%) were pretreated by somatostatin agonists or dopamine agonists. Nearly $16 \%$ patients had microadenomas, whereas $84 \%$ had macroadenomas. Knosp grades 3, and 4 were observed in $36 \%$ patients. Surgical removal was assessed by the neurosurgeon to be likely complete in $45 \%$, uncertain in $30 \%$, and incomplete in $25 \%$ patients. Of the included patients, 112 were operated between 1997 and 2008, and 55 between 2008 and 2014. In all, 18/167 patients underwent radiation therapy during the follow-up. Among patients operated from 2008 to 2014, 8
(14\%) were considered to present pathological aggressive features $(\mathrm{Ki} \geq 3)$.

\subsection{Distribution of the different grades during the follow-up}

Of the 167 included patients, 167 presented analyzable data in the early postoperative period (EPP) and at 3 months, whereas 142 were analyzable at 1 year. And 139 were followed-up for more than 1 year. Some patients presented incomplete data in the follow-up. The distribution of patients in each grade is detailed in Fig. 1.

\subsection{Grade variation during the follow-up}

Including all the patients with all grades, 58/167 (35\%) moved to another grade from EPP to 3 postoperative months, 37/142 (26\%) moved to another grade from 3 postoperative months to 1 postoperative year and 12/130 (9\%) from one postoperative year to last follow-up. From EPP or M3 to last follow-up ( $>1$ year) respectively $54 / 139$ (39\%) and 33/138 (24\%) moved to another grade (Fig. 2).

\subsection{Grade I patient outcome during the follow-up}

Twenty-two percent of EPP grade I patients moved to another grade during the first 3 postoperative months, whereas 15\% moved to another grade between 3 months and 1 year after the surgery. After the first postoperative year, only $2 \%$ of grade I patients moved to another grade (Fig. 2).

Among the grade I patients at EPP, 3\% escalated to grade II and 9\% to grade III-IV at the end of follow-up (Fig. 3). At 3 months, 5\% escalated to grade II and 7\% to grade III-IV (Fig. 4). At 1 year only $2 \%$ escalated to grade III-IV (Fig. 5).

\subsection{Grade II patient outcome during the follow-up}

Fifty-seven percent of EPP grade II patients moved to another grade in the first 3 postoperative months, and then $67 \%$ moved to another grade between 3 postoperative months and 1 postoperative year. Forty-seven per cent of grade II patients at 1 year moved to another grade after the first postoperative year. Between EPP or M3 and last follow-up (>1 year) respectively $74 \%$ and $75 \%$ of patients moved to another grade (Fig. 2).

In the EPP, among the 49 grade II patients with a follow-up $>1$ year: $58 \%$ moved to grade I, $20 \%$ remained at grade II, and $22 \%$ escalated to grade III-IV (Fig. 3). At 3 months, among the 33 grade II 


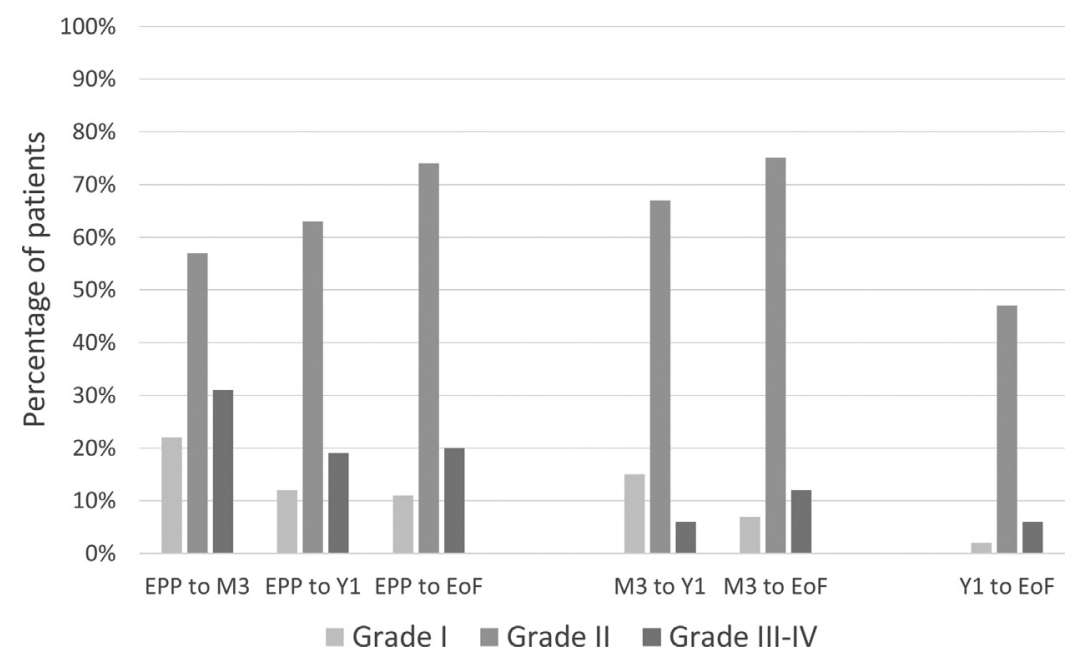

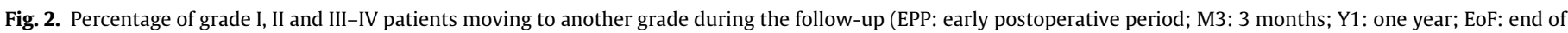
follow-up).

In the EPP

\section{A Grade I patients $\mathrm{n}=46$}
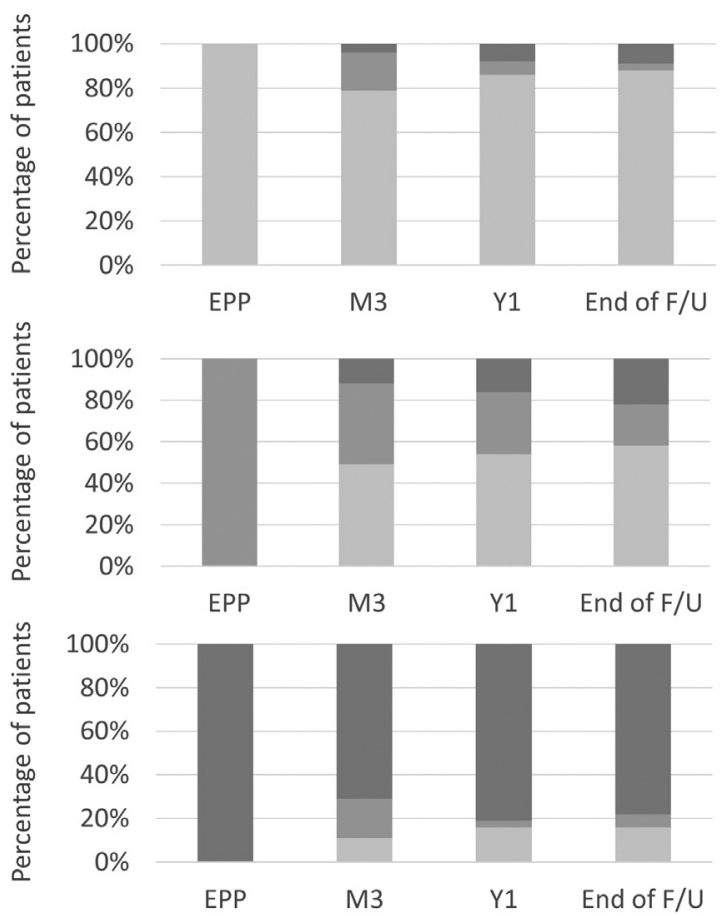

Grade I - Grade II — Grade III, IV, IR

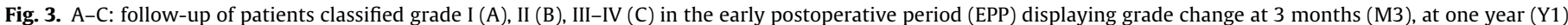
and at the end of follow-up (E of F/U).

patients with followed-up for > 1 year: $47 \%$ moved to grade I, $25 \%$ remained at grade II, and $28 \%$ escalated to grade III, IV, or IR (Fig. 4). At 1 year, among the 19 grade II patients with a follow-up > 1 year: $32 \%$ moved to grade I, 58\% remained at grade II, $10 \%$ escalated to grade III, IVAR, or IVB (Fig. 5).

\subsection{Grade III-IV patient outcome during the follow-up}

Thirty-one percent of grade IVA patients moved to grade I or II during the first 3 postoperative months, and $6 \%$ of grade III-IVA-B moved to grade I-II between 3 postoperative months and 1 postoperative year, as between 1 postoperative year and last follow-up (Fig. 2).
Among the 55 grade IV patients at EPP with a follow-up > 1 year: $20 \%$ moved to grade I or II without proven recurrence at the end of follow-up (Fig. 3). Among the 50 grade IV patients at 3 months with a follow-up > 1 year: $14 \%$ moved to grade I-II and $86 \%$ remained at grade III, IV, or IR (Fig. 4). Among the 54 grade III-IV patients with a follow-up for $>1$ year: only $6 \%$ moved to grade I-II and $94 \%$ remained at grade III, IV, or IR (Fig. 5).

\subsection{Factors influencing the grade change during the follow-up}

\subsubsection{Grade I patients}

Irrespective of the period (EPP, 3 months, and 1 year), grade I patients presented a low rate of recurrence $(9 \%, 7.5 \%$, and $2 \%$, 
At $\mathrm{M} 3$

A Grade I patients

B Grade II patients

C Grade III-IV patients
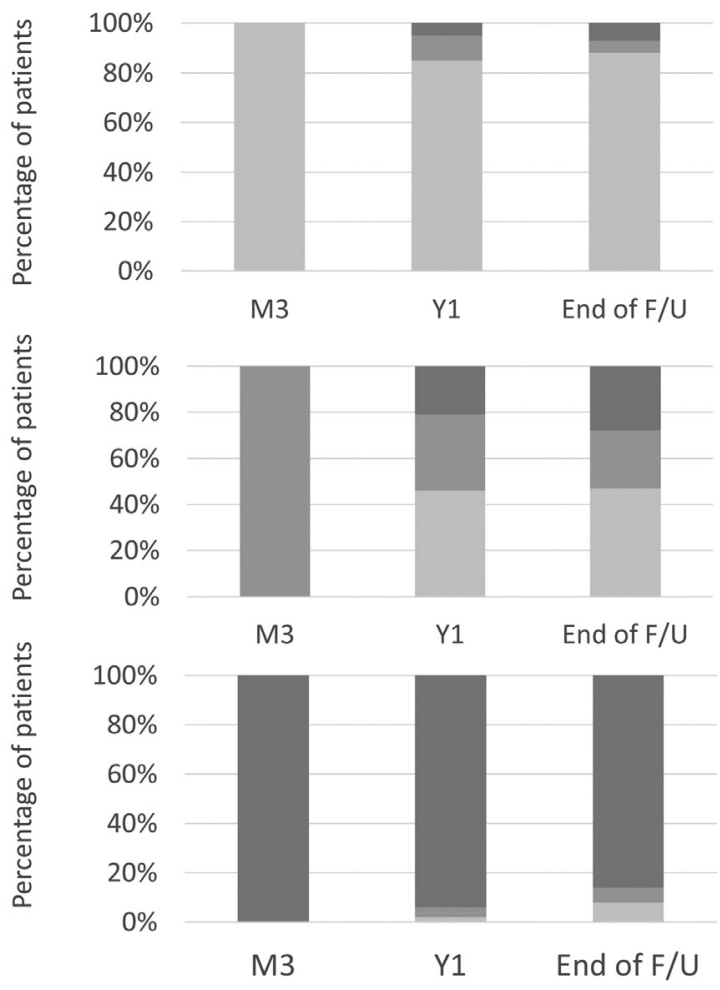

-Grade I Grade II Grade IR-III-IV

Fig. 4. A-C: follow-up of patients classified grade I (A), II (B), and III-IV (C) at 3 months displaying grade change at one year (Y1) and at the end of follow-up (E of F/U).

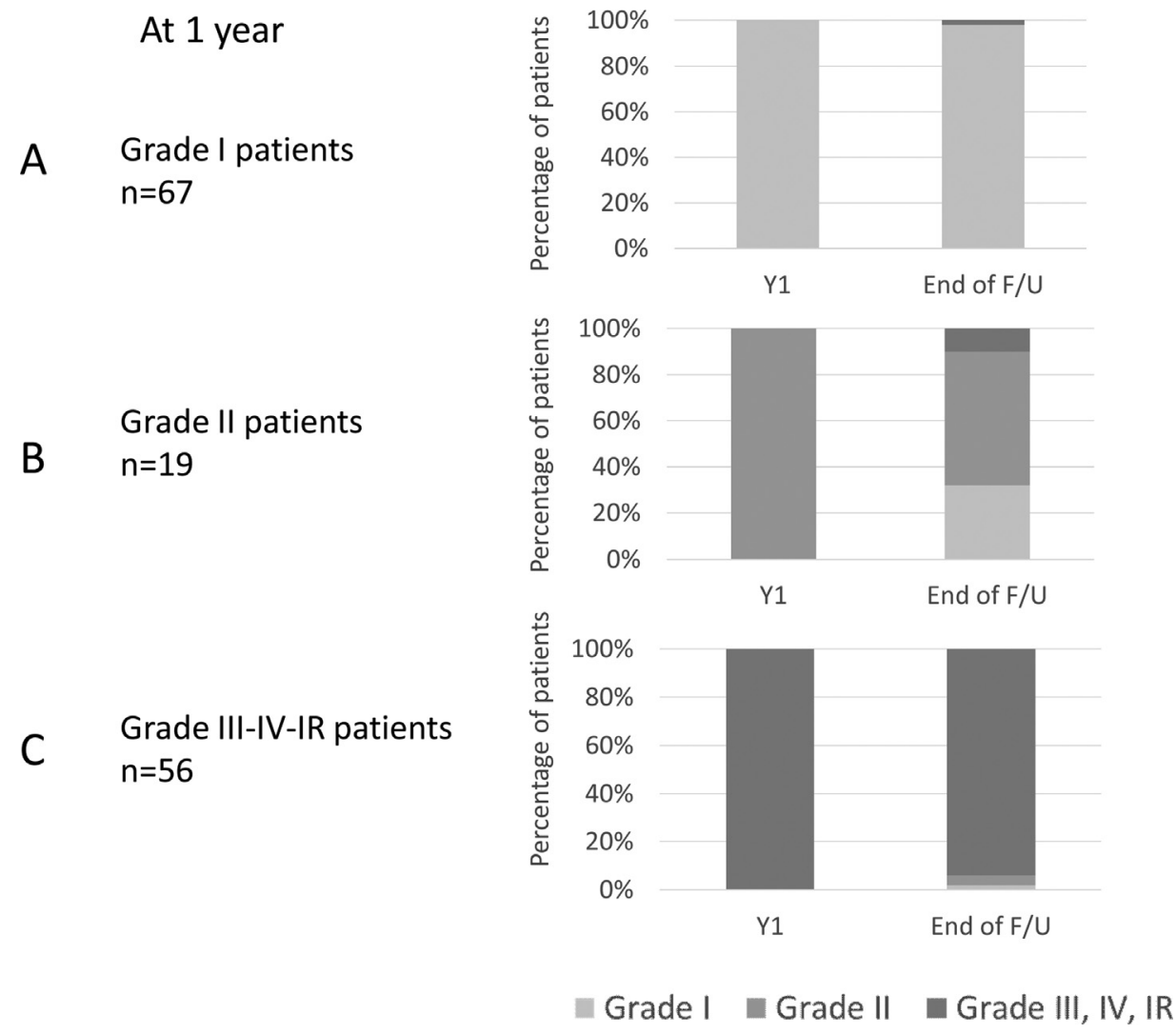

Fig. 5. A-C. Follow-up of patients classified grade I (A), II (B), III-IV (C) at one year (Y1) displaying grade change at the end of follow-up (E of F/U). 
Table 2

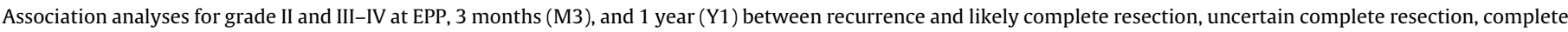

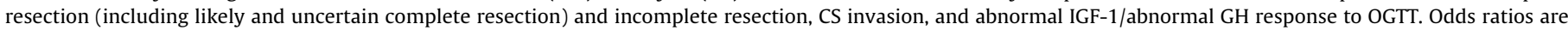
displayed with 95\% confidence interval (CI). A two-sided $P$-value of $<0.05$ was considered to indicate statistical significance.

\begin{tabular}{|c|c|c|c|c|c|c|}
\hline Grade & Analyzed Factor & Delay & OR & Lower 95\% & Upper 95\% & pval \\
\hline \multirow[t]{12}{*}{ Grade II } & \multirow[t]{3}{*}{ Complete resection } & EPP & 0.154 & 0.032 & 0.681 & 0.014 \\
\hline & & M3 & 0.133 & 0.022 & 0.68 & 0.015 \\
\hline & & Y1 & 0.161 & 0.009 & 2.57 & 0.181 \\
\hline & \multirow[t]{3}{*}{ SC invasion } & EPP & 4.241 & 1.091 & 17.464 & 0.037 \\
\hline & & M3 & 3.479 & 0.761 & 17.188 & 0.108 \\
\hline & & Y1 & 9.667 & 0.915 & 149.543 & 0.059 \\
\hline & \multirow[t]{3}{*}{ Abnormal IGF-1 } & EPP & 0.448 & 0.116 & 1.669 & 0.229 \\
\hline & & M3 & 0.421 & 0.089 & 1.874 & 0.255 \\
\hline & & Y1 & 0.058 & 0.003 & 0.701 & 0.025 \\
\hline & \multirow[t]{3}{*}{ Abnormal GH } & EPP & 2.232 & 0.599 & 8.642 & 0.229 \\
\hline & & M3 & 2.373 & 0.534 & 11.191 & 0.255 \\
\hline & & Y1 & 17.22 & 1.427 & 350.28 & 0.025 \\
\hline \multirow[t]{6}{*}{ Grade III-IV } & \multirow[t]{3}{*}{ Likely complete resection } & EPP & 0.151 & 0.037 & 0.568 & 0.005 \\
\hline & & M3 & 0.452 & 0.087 & 2.894 & 0.373 \\
\hline & & $\mathrm{Y} 1$ & 1.565 & 0.134 & 217.111 & 0.762 \\
\hline & \multirow[t]{3}{*}{ SC invasion } & EPP & 7.671 & 2.034 & 35.441 & 0.002 \\
\hline & & M3 & 4.067 & 0.796 & 25.818 & 0.092 \\
\hline & & Y1 & 3.286 & 0.406 & 37.976 & 0.258 \\
\hline
\end{tabular}

The character are in bold when $P$-value $<0.05$.

respectively). Combining grade I patients and (likely or uncertain) complete resection led to a very low rate of long-term recurrence $(9.5 \%, 3 \%$, and $0 \%$, respectively). CS invasion did not significantly impact the rate of recurrence in grade I patients in this series (Table 2; Suppl. Table 1 and 2).

\subsubsection{Grade II patients}

Irrespective of the period, likely complete resection was correlated to a low rate of recurrence in grade II patients $(0 \%, 6.5 \%$, and $0 \%$ at EPP, 3 months, and 1 year, respectively). The rate of recurrence was higher in patients with uncertain complete or incomplete resection (28.5\% and $50 \%$, respectively, vs. $0 \%$ in patients with likely complete resection at 1 year (Table 1 and Suppl. Table. 1 and 2). CS invasion also increased the rate of recurrence in grade II patients irrespective of the period ( $50 \%$ vs. $6.5 \%$ at 1 year). Interestingly, patients classified in grade II because of an elevated GH concentration after OGTT presented a higher rate of recurrence compared to patients classified in grade II because of an elevated IGF-1 concentration (at 1 year, $40 \%$ of recurrence if abnormal GH vs. $7 \%$ if abnormal IGF-1 (Table 2 and Suppl. Table 1). Eleven out of 15 grade II patients at the end of follow-up were pretreated by somatostatin or dopamine agonists. Only one of these 15 patients was grade I at the EPP and this patient did not receive any pretreatment. Therefore, pretreatment does not seem to impact on EPP assessment in grade II patients. No significant difference was found comparing peroperative IGF-1 level in non-pretreated patients comparing grade I with grade II patients at the EPP (data not shown).

\subsubsection{Grade III-IV patients}

The percentage of grade III-IV patients remaining uncured at the end of follow-up was high irrespective of the period. In the EPP, in patients with likely complete surgical resection, only $46 \%$ grade IV patients remained at grade III-IV against $78 \%$ and $100 \%$ at 3 months and 1 year, respectively (Table 2 and Suppl. Table 3). Conversely, grade IV patients at 3 months and 1 year presented high rate of persistent disease even in case of likely complete tumor resection (respectively $74 \%$ and $100 \%$ of uncured patients at the last followup). In grade IV patients, except in the EPP, cavernous sinus invasion did not impact significantly the rate of persistent disease (Table 2 and Suppl. Table 3). Among the 56 grade III-IV patients at the end of follow-up, 33 (59\%) were pretreated; 3/56 were grade I at the EPP and $3 / 3$ of these grade I patients were pretreated. Moreover, $11 / 56$ patients were grade II at the EPP and $6 / 11$ of these grade II patients were pretreated. Correlation analysis with pretreatment and grade I and II at EPP displayed a $P$-value at respectively 0.0001 and 1.25. These results suggest that pretreatment could impact on GH and IGF-1 in the EPP in non-cured patients.

\section{Discussion}

The status of $\mathrm{GH}$ hypersecretion (remission or persistence) varies during the first year after surgery. This is exemplified by the fact that a third of patients changed their status between immediate post-surgical period and 3 months, a fourth between 3 months and 1 year, and almost $10 \%$ after 1 year. For instance, despite stringent criteria of remission, $22 \%$ of supposedly cured grade I patients immediately after surgery, and $15 \%$ of grade I patients considered cured 3 months after surgery finally became GH/IGF-1 discordant or recurred during the follow-up. Previous literature data mainly focus on the remission/failure to describe surgical result, a view that is highly simple, but the present study highlight that postoperative outcome considering GH and IGF-1 biological status remain more complex and could lead to undefined and uncertain situations. The present classification is helpful in assessing the probability of grade change during the follow-up and therefore to predict endocrinological patient outcome or in contrast to highlight the final patient outcome uncertainty, which could help clinicians in their current practice. In this study, we highlight the fluctuating postoperative endocrinological status of patients operated for acromegaly. For instance, $12 \%$ of grade I, $80 \%$ of grade II, and $20 \%$ of grade IV at the EPP moved to another grade at the end of follow-up, whereas $12 \%$ of grade I, $75 \%$ of grade II, and $14 \%$ of grade IV at 3 months moved to another grade at the end of follow-up.

The outcome in grade I patients was excellent. The secretory status of the majority of grade I patients seem to be definitely determined 1 year after surgery. Combination with neurosurgeon peroperative impression of (likely or uncertain) complete removal led to a remission rate of $>90 \%$ at the end of follow-up. In these patients, adding the five-tiered classification using invasion and proliferation would probably help determine the optimal longterm monitoring modalities, especially for the $10 \%$ patients who will change status during the follow-up [7]. This was not possible in our study, as the pathology samples from 1997 to 2008 did not include adequate proliferation data.

Grade II patients, i.e., those with discordant GH and IGF-1 levels, are the most difficult to manage, as shown by the high 
number of patients with biological status change during follow-up, even after the first postoperative year. In literature, these discordant patients with uncertain remission remain rarely described $[2,3,8]$. However, they represent a non-negligible part of patients (35.5\% immediately after surgery, $24.5 \%$ at 3 months, and $11-13.5 \%$ during the remaining follow-up), and the consequences of such discordance remain unclear in terms of persistence or worsening of comorbidities. Nevertheless, the outcome of these patients seems favorable: approximately $50 \%$ of grade II patients at EPP, M3, and Y1 moved to grade I. After one year, only $10 \%$ of grade II recurred. In the first postoperative weeks, IGF-1 could remain high given its slower blood level decrease compared to $\mathrm{GH}$. This probably explains the favorable outcome of approximately one half of grade II patients, particularly in case of abnormal IGF-1 compared to patients with abnormal $\mathrm{GH}$ in the 3 first postoperative months. Progressive normalization of IGF- 1 also probably at least explains the decrease in the percentage of grade II patients during the first postoperative year. But this remains unclear given the lack of difference in preoperative IGF-1 level comparing grade I and grade II patients at the EPP. Nevertheless, it is interesting to note that grade II patients' outcome remains uncertain even after one postoperative year. The remaining grade II patients' outcome was quite shared between persistent grade II patients without demonstrated recurrence, and grade III-IV patients with proven recurrence. CS invasion as uncertain complete or incomplete removal significantly increased recurrence rate and should be considered as relevant prognosis factors, in accordance with the five-tiered classification [7]. Interestingly, expert neurosurgeon peroperative finding of complete or incomplete resection, which includes a part of subjectivity, appears relevant in assessing the risk of recurrence. Abnormal OGTT or high GH level seemed more predictive and specific of recurrence than high IGF-1 level in the third first postoperative months but also at one year. Previous literature data reported discordant results on this point [8-14]. Verrua et al. suggested that the $\mathrm{GH}$ nadir $<0.4 \mathrm{ng} / \mathrm{L}$ on OGTT may be too low and that IGF-1 level 3 months after surgery would be more robust to assess remission [15]. Grade II definition remains directly related to selected biological thresholds and the impact of the IGF-1 and GH dosage technics should be considered. Thresholds determination remains challenging and currently still debated [2]. Establishment of more stringent biological thresholds will lead to a higher specificity but in contrast will increase the number of discordant grade II patients and conversely [3,15]. In this study, pretreatment by somatostatin and dopamine agonists does not seem to impact the EPP assessment in the grade II patients. Grade II patients should in any case benefit from a long-term follow-up, which is also a limit of the present study and which should be of high interest.

Grade III, IV, and IR patients represented 37\%, 32\%, 39.5\%, and $40 \%$ at EPP, M3, Y1, and the end of follow-up, respectively. At EPP and 3 months, $20 \%$ and $12 \%$ of grade IV patients moved to grade I-II at the end of follow-up, respectively. Moreover, $31 \%$ grade IV patients move to another grade between EPP and 3 months, which could be at least partially explained by pretreatment with somatostatin or dopamine analogues. This is also probably related to the variable postoperative decrease in $\mathrm{GH}$ and IGF-1 blood level. In the EPP, likely complete tumor resection as lack of cavernous sinus invasion significantly decreased the risk of recurrence. Conversely, after 1 postoperative year, only $6 \%$ patients moved to another grade. The secretory status of most grade III-IV patients seems to be definitely determined at 1 year after surgery. At 3 months and 1 year, grade IV patients mostly remained uncured irrespective of cavernous sinus invasion or neurosurgeon observations.

To conclude, we analyzed the timeframe postoperative GH/IGF1 secretory status with the help of a classification that should also help clinicians to better define the certainty and uncertainty of their patients' outcome. Grade I and III-IV patients' outcome seems defined after the first postoperative year. In contrast, for discordant grade II patients, the outcome despite quite favorable remains undefined and difficult to predict even after the first postoperative year.

\section{Funding}

\section{No Funding.}

\section{Ethical Approval}

All procedures performed in studies involving human participants were in accordance with the 1964 Helsinki declaration and its later amendments.

\section{Disclosure of interest}

The authors declare that they have no competing interest.

\section{Appendix A. Supplementary data}

Supplementary data associated with this article can be found, in the online version, at: https://doi.org/10.1016/j.ando.2019.11.002.

\section{References}

[1] Rochette C, Graillon T, Albarel F, Morange I, Dufour H, Brue T, et al. Increased risk of persistent glucose disorders after control of acromegaly. J Endocr Soc 2017;1:1531-9.

[2] Espinosa-de-los-Monteros AL, Mercado M, Sosa E, Lizama O, Guinto G, Lopez-Felix B, et al. Changing patterns of insulin-like growth factor-I and glucose-suppressed growth hormone levels after pituitary surgery in patients with acromegaly. J Neurosurg 2002;97:287-92.

[3] Espinosa-de-Los-Monteros AL, Sosa E, Cheng S, Ochoa R, Sandoval C, Guinto $\mathrm{G}$, et al. Biochemical evaluation of disease activity after pituitary surgery in acromegaly: a critical analysis of patients who spontaneously change disease status. Clin Endocrinol (Oxf) 2006:64:245-9.

[4] Holdaway IM, Bolland MJ, Gamble GD. A meta-analysis of the effect of lowering serum levels of GH and IGF-I on mortality in acromegaly. Eur J Endocrinol 2008;159:89-95.

[5] Albarel F, Castinetti F, Morange I, Conte-Devolx B, Gaudart J, Dufour H, et al. Outcome of multimodal therapy in operated acromegalic patients, a study in 115 patients. Clin Endocrinol (Oxf) 2013;78:263-70.

[6] Heinze G. A comparative investigation of methods for logistic regression with separated or nearly separated data. Stat Med 2006;25:4216-26.

[7] Raverot G, Dantony E, Beauvy J, Vasiljevic A, Mikolasek S, Borson-Chazot F, et al Risk of recurrence in pituitary neuroendocrine tumors: a prospective study using a five-tiered classification. J Clin Endocrinol Metab 2017:102:3368-74.

[8] Freda PU. Monitoring of acromegaly: what should be performed when GH and IGF-1 levels are discrepant? Clin Endocrinol (Oxf) 2009;71:166-70.

[9] Cazabat L, Souberbielle JC, Chanson P. Dynamic tests for the diagnosis and assessment of treatment efficacy in acromegaly. Pituitary 2008;11:129-39.

[10] Colao A, Pivonello R, Cavallo LM, Gaccione M, Auriemma RS, Esposito F, et al. Age changes the diagnostic accuracy of mean profile and nadir growth hormone levels after oral glucose in postoperative patients with acromegaly. Clin Endocrinol (Oxf) 2006;65:250-6.

[11] Arafat AM, Mohlig M, Weickert MO, Perschel FH, Purschwitz J, Spranger J, et al. Growth hormone response during oral glucose tolerance test: the impact of assay method on the estimation of reference values in patients with acromegaly and in healthy controls, and the role of gender, age, and body mass index. J Clin Endocrinol Metab 2008;93:1254-62.

[12] Ronchi CL, Arosio M, Rizzo E, Lania AG, Beck-Peccoz P, Spada A. Adequacy of current postglucose $\mathrm{GH}$ nadir limit $(<1 \mathrm{microg} / \mathrm{L})$ to define long-lasting remission of acromegalic disease. Clin Endocrinol (Oxf) 2007;66:538-42.

[13] Mavromati M, Kuhn E, Agostini H, Brailly-Tabard S, Massart C, Piketty ML, et al. Classification of patients with GH disorders may vary according to the IGF-I assay. J Clin Endocrinol Metab 2017;102:2844-52.

[14] Giustina A, Chanson P, Bronstein MD, Klibanski A, Lamberts S, Casanueva FF, et al. A consensus on criteria for cure of acromegaly. J Clin Endocrinol Metab 2010;95:3141-8.

[15] Verrua E, Ferrante E, Filopanti M, Malchiodi E, Sala E, Giavoli C, et al. Reevaluation of acromegalic patients in long-term remission according to newly proposed consensus criteria for control of disease. Int J Endocrinol 2014;2014:581594 